\title{
SISTEM PESAN MAKANAN VIA BLUETOOTH DENGAN INTERFACE ANDROID BERBASIS ARDUINO UNO
}

\author{
Sudaryono ${ }^{1}$ \\ Muhamad Gunawan ${ }^{2}$ \\ Hilmi Nugraha ${ }^{3}$ \\ ${ }^{1}$ Dosen STMIK Raharja, ${ }^{2,3}$ Mahasiswa STMIK Raharja \\ 1,2,3 Jl.Jendral Sudirman No.40,modern,Tangerang,021-5529692 \\ Email:sudaryono@raharja.infol, ,gunawan@raharja.info $^{2}$,hilmi@raharja.info ${ }^{3}$
}

\begin{abstract}
ABSTRAK
Perkembangan teknologi khususnya pada perangkat mobile sangat mendukung dalam menjalankan aktivitas bisnis dan tidak terkecuali pada bisnis restoran. Dalam menghadapi persaingan bisnis pihak perusahaan harus mencari strategi agar dapat menarik minat konsumen. Adapun teknologi informasi yang saat ini sedang berkembang adalah android. Android merupakan sistem operasi mobile menggunakan versi modifikasi dari kernel linux. Tidak hanya dipakai seperti mobile pada umumnya, android kini banyak digunakan untuk keperluan lainnya seperti pemesanan makanan di restoran atau tempat makan lainnya. Penggunaan mobile android untuk pemesanan makanan dapat membantu proses bisnis dalam sebuah tempat makan, Tujuan dari penelitian ini adalah membuat alat untuk mempermudah pemesanan makanan dengan menggunakan modul sistem minimum Arduino Uno. serta Bahasa Pemrograman C. Hasil implementasi dalam Proyek Akhir ini adalah berupa alat pesan makanan via bluetooth dengan interface android. Kemudian makanan yang dipesan akan menghampiri pembeli secara otomatis dengan menggunakan motor servo dan sensor LDR.
\end{abstract}

Kata Kunci: Pesan Makanan, Arduino Uno, Android, Motor Servo, Sensor LDR

\begin{abstract}
Technological developments, especially on mobile perangat very supportive in conducting business activities and not the exception in the restaurant business. In the face of competition of business the company should look for strategies in order to attract consumers. As information technology is currently being developed is android. Android is a mobile operating system using a modified version of the Linux kernel. Not only used as mobile in general, android is now widely used for other purposes such as ordering food in a restaurant or other eating places. Android mobile usage for ordering food can help a business process in a place to eat. The aim of this study is to make a tool to simplify ordering food using minimum system module Arduino Uno. as well as the programming language $C$. The results of the implementation of the Final Project is a tool food messages via bluetooth with android interface. Then the food ordered will be up to the buyer automatically using servo motors and sensors $L D R$.
\end{abstract}

Keywords: Food, Arduino Uno , Android, Servo Motor, Sensor LD

Vol.2 No.1 - Februari 2016 


\section{PENDAHULUAN}

Perkembangan teknologi khususnya teknologi informasi pada masa sekarang dirasakan sudah semakin maju pesat, misalnya perkembangan sistem kontrol otomatis berbasis Mikrokontroler dengan dilengkapi sensor, Mikrokontroler adalah prosessor yang sudah dilengkapi port input/output (I/O), dan memori. Mikrokontroler ini dapat digunakan bersama sensor-sensor maupun alat mekanis lainnya agar dapat bekerja secara otomatis dan dapat meringankan pekerjaan manusia, misalnya: menyalakan mesin motor secara otomatis, menyalakan alat-alat rumah tangga secara otomatis, menggerakkan lengan robot, menggerakkan trolley, blower, kompressor, bor, mixer dan banyak lagi, di mana mereka rela mengeluarkan biaya lebih untuk membiayai sebuah penelitian dan modifikasi peralatan dengan tujuan menghasilkan peralatanperalatan yang memiliki tingkat efektifitas lebih baik dan hasil efektif.

Hal tersebut dapat dilihat dari banyaknya penemuan-penemuan baru di berbagai bidang ilmu contohnya di bidang industri restoran. sebuah alat pesan makanan secara otomatis menggunakan bluetooth dengan interface android dan sensor infrared berbasis mikrokontroler arduino uno telah dibuat. Sistem pesan makanan dengan menggunakan android pada restoran dapat mempermudah dan mempersingkat waktu manusia dalam menjalankan roda bisnis, meningkatkan pelayanan, dimana mobilitas manusia semakin tinggi dan ketepatan waktu menjadi faktor utama yang diperlukan pada zaman tekhnologi informasi. Untuk itu dibutuhkan suatu alat otomatis yang dapat menggerakkan suatu mesin secara otomatis dengan cepat dan aman agar dapat menambah efisiensi waktu.

Vol.2 No.1 - Februari 2016

\section{PERMASALAHAN}

1. Bagaimana Mikrokontroler arduino uno dapat berinteraksi dengan smartphone android?

2. Bagaimana cara arduino uno membuat meja makanan berputar dan pesanan yang telah dipesan otomatis menghampiri customer?

3. Aplikasi apa yang digunakan untuk mengontrol sistem pesan makanan?

\section{LITERATURE REVIEW}

Dalam upaya mengembangkan dan membangun sistem prsan makanan via Bluetooth dengan interface android berbasis arduino uno ini perlu dilakukan literature review (study pustaka), sebagai salah satu dari penerapan metode penelitian yang akan dilakukan. Terdapat banyak penelitian lain yang berkaitan dengan SKRIPSI penulis yang menunjang untuk penelitian yang akan dilakukan, diantaranya:

1. Penelitian Tugas Akhir yang dilakukan oleh Dedy Arisandy, pada tahun (2013), dari Universitas Jember yang berjudul "PEMESAN MAKANAN OTOMATIS MENGGUNAKAN RF

BERBASIS

MIKROKONTROLER

Atmega8535". Pada penelitian ini membahas alat dengan mengunakan sistem pemesanan menggunakan alat elektronika. Alat tersebut cara kerjanya yaitu alat pemesan makanan diletakkan di meja restoran,alat tersebut terdiri dari beberapa rangkaian elektronika diantaranya yaitu Mikkrokontroler, RF, Keypad, LCD. Mikrokontroler difungsikan sebagai otak aplikasi alat ini dimana mikrokontroler berfungsi sebagai pengubah data dari keypad menjadi data serial. RF difungsikan 
sebagai pengirim data yang sudah falid akan dikirim ke RF pada meja operator.

2. Penelitian pada Jurnal yang dilakukan oleh Anggia Kusumawaty, pada tahun (2012), dari Universitas Gunadarma yang berjudul "APLIKASI

PEMESANAN MAKANAN PADA RESTORAN BERBASIS ANDROID DAN PHP MENGGUNAKAN PROTOKOL JSON". Pada penelitian ini membahas Program aplikasi mobile Pemesanan Makanan pada Restoran untuk handphone dengan sistem operasi Android yang menggunakan bahasa pemrograman Java telah berhasil dibuat. Aplikasi Pemesanan Makanan pada Restoran ini dapat memudahkan pelayan dalam mencatat pesanan pelanggan pada setiap Restoran. Pelayan tidak perlu membawa selembar kertas dan alat tulis untuk mencatat pesanan pelanggan, tetapi menggunakan media handphone untuk mencatat pesanan pelanggan.

3. Penelitian Tugas Akhir yang dilakukan oleh Ruth Angelia Sidabutar, pada tahun (2012), dari Politeknik Negeri Medan yang berjudul "PERANCANGAN DAN PEMBUATAN APLIKASI PEMESANAN MENU MAKANAN DAN MINUMAN BERBASIS CLIENT SERVER PADA RUMAH MAKAN AYAM PENYET SURABAYA (SERVER)". Pada penelitian ini membahas aplikasi pemesanan menu pada Rumah Makan Ayam Penyet Surabaya berbasis client server menggunakan mobile android adalah sebuah aplikasi pemesanan menu memakai computer dibagian dapur, admin, dan kasir dihubungkan melalui jaringan wireless. Bahasa pemrograman yang digunakan dalam perancangan aplikasi adalah Microsoft Visual Basic.Net 2010 dan menggunakan database Mysql. Metode perancangan yang digunakan adalah System Development Life Cycle yang merupakan proses pengembangan system melalui perencanaan, analisis, desain, uji coba dan evaluasi, implementasi.

4. Penelitian pada Jurnal yang dilakukan oleh Priscilia Miraditya, Harianto, dan Madha Christian Wibowo, pada tahun (2014), dari STMIK STIKOM Surabaya yang berjudul "RANCANG BANGUN ALAT PEMESANAN MENU MAKANAN OTOMATIS BERBASIS

MICROCONTROLLER DENGAN KOMUNIKASI TCP/IP". Pada penelitian ini membahas sebuah perangkat yang tersedia di masing-masing meja, terdiri dari moving sign display yang berfungsi menampilkan data dan keypad yang berfungsi untuk memasukkan data. Sehingga pelanggan tidak perlu menunggu lama untuk memesan menu yang diinginkan. Mikrokontroler yang dipergunakan alat ini berguna sebagai slave yang menjalankan perintah dari server (PC). Mikrokontroler umumnya bekerja berdasarkan I/O (Input/Output) yang digunakan.

5. Penelitian SKRIPSI yang dilakukan Yusuf Effendi, pada tahun (2015), dari Universitas Muria Kudus yang berjudul "APLIKASI PEMESANAN MAKANAN, LAGU DAN PEMANDU KARAOKE BERBASIS ANDROID PADA 
CAFÉ NEW STAR KUDUS". Pada penelitian ini membahas Aplikasi yang terdiri dari dua bagian yaitu aplikasi sistem server pada komputer operator dan aplikasi pemesanan berbasis android pada yang terkoneksi dengan computer operator melalui jaringan internet. Fitur-fitur yang tersedia pada aplikasi ini untuk klien adalah melihat daftar menu makanan dan minuman, melihat tarif durasi lagu dan daftar Pemandu karaoke, melakukan pemesanan dengan disertai harga per itemnya. Sedangkan untuk operator bisa menambah dan mengedit menu makanan dan minuman, daftar lagu dan pemandu karaoke. Selain itu bisa melihat daftar pesanan dan kemudian bias mencetak sebagai nota tagihan yang harus dibayar oleh pengunjung.

Dari lima literature review diatas, dapat diketahui bahwa penelitian tentang mikrokontroler, sistem pesan makanan sudah banyak dibahas. Dalam beberapa sumber literature review tersebut saya mengambil dari literature nomor 1 karena kesamaan pemesanan makanan secara otomatis, pengembangan saya dengan menggunakan sensor LDR dan menggunakan android sebagai interface tampilan menu makanannya.

\section{PEMECAHAN MASALAH}

Setelah mengamati dan meneliti dari beberapa permasalahan yang ada, terdapat beberapa alternatif pemecahan dari permasalahan yang dihadapi, antara lain:

a. Membuat sistem pemesanan makanan yang dapat otomatis menghapiri customer saat makanan tersebut dipesan melalui Smartphone android, sehingga dapat memudahkan customer selama proses pemesanan makanan.

b. Membuat sistem yang dapat menghemat waktu dan tampilan aplikasi yang mudah digunakan dengan interface android.

c. Membuat sistem yang dapat dilihat hasil penjualan dengan memanfaatkan database sebagai media untuk menyimpan data hasil penjualan.

\section{IMPLEMENTASI \\ Flowchart Sistem}

Dalam pembuatan sistem dan perancangan program dapat digambarkan dalam bentuk flowchart sehingga dapat mempermudah dalam melakukan dan merancang langkahlangkah atau proses dengan benar. Adapun bentuk dari flowchart keseluruhan dari sistem yang dibuat dapat dilihat pada gambar berikut.

Vol.2 No.1 - Februari 2016 


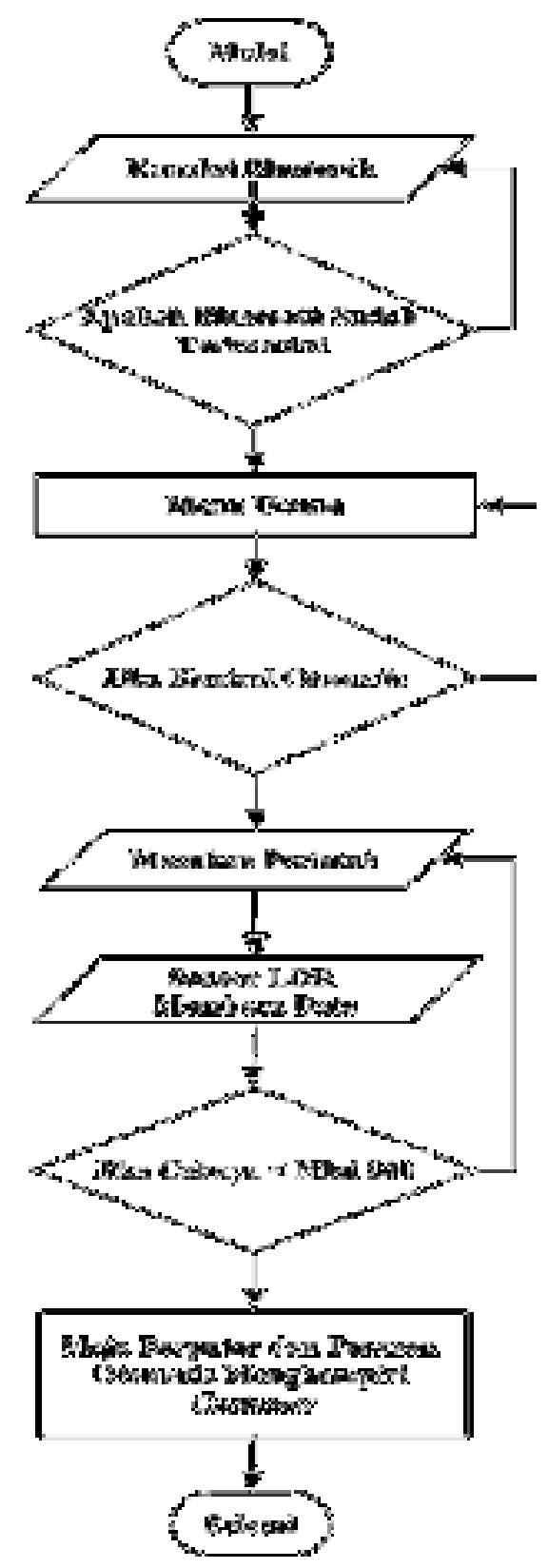

Gambar 1. Flowchart sistem menampilkan daftar makanan yang akan dipesan, dan rangkaian catu daya 5 Volt sebagai sumber tegangan bagi komponen-komponen tersebut.

Agar mempermudah dalam menjelaskan perancangan perangkat keras, maka di gambarkan alur dan cara kerja perangkat keras pada rangkaian keseluruhan pada gambar 2 di bawah ini:

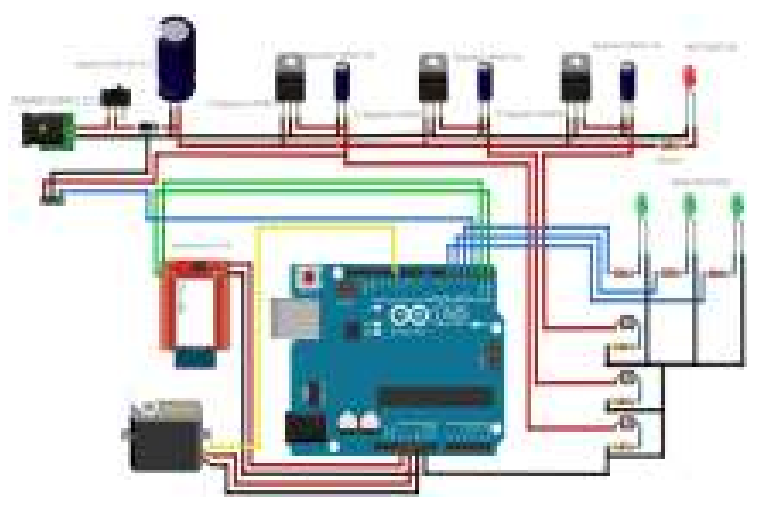

\section{Gambar 2. Rangkaian Sistem Keseluruhan}

Rangkaian keseluruhan dari sistem ini merupakan penggabungan dari beberapa rangkaian seperti arduino uno, modul Bluetooth HC-05 dengan komunikasi serial untuk komunikasi antara arduino uno dan smartphone, motor servo sebagai penggerak meja pesanan, dan sebagai tambahan IC converter 5 volt ke 3 volt. Tegangan 3 volt digunakan modul Bluetooth HC-05.

\section{Arduino Uno}

\section{Perancangan Hardware}

Perancangan hardware untuk merancang sistem pemesanan makanan ini menggunakan komponen arduino uno sebagai modul untuk melakukan proses, modul Bluetooth HC-05 sebagai media komunikasi serial dengan smartphone, motor servo sebagai penggerak meja pesanan, smartphone android sebagai media interface untuk

\section{Vol.2 No.1 - Februari 2016}

Arduino uno adalah kit elektronik atau papan rangkaian elektronik open source yang di dalamnya terdapat komponen utama, yaitu sebuah chip mikrokontroller dengan jenis AVR dari perusahaan Atmel. Arduino uno memiliki 14 pin input dari output digital dimana 6 pin input tersebut dapat digunakan sebagai output PWM (Pulse Widht Modulation) dan 6 pin input 
analog, $16 \mathrm{MHz}$ osilator kristal, koneksi USB, jack power, ICSPheader, dan juga tombol reset

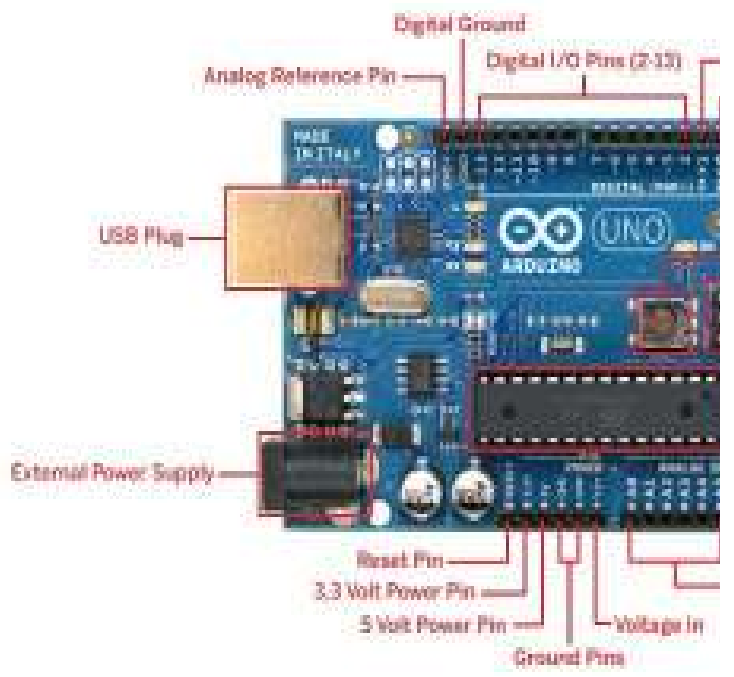

Gambar 3. Arduino Uno

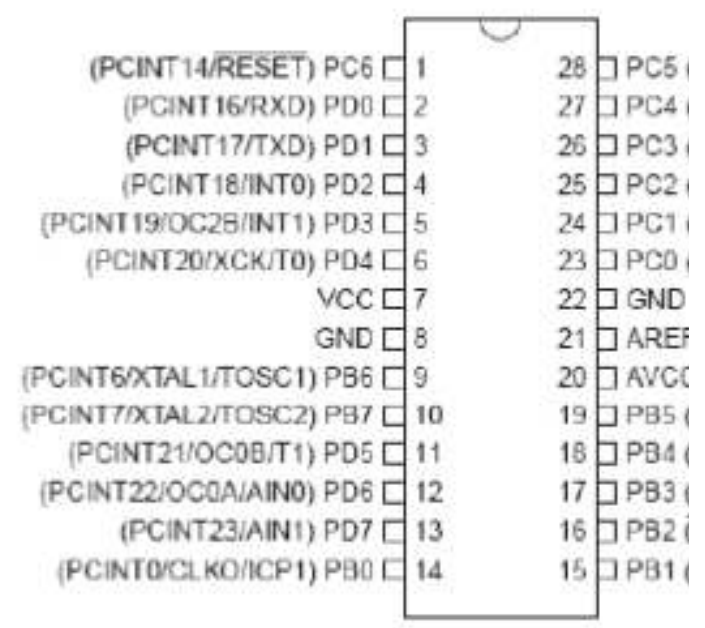

Gambar 4. Konfigurasi Pin ATMega 328

\section{Modul Bluetooth HC-05}

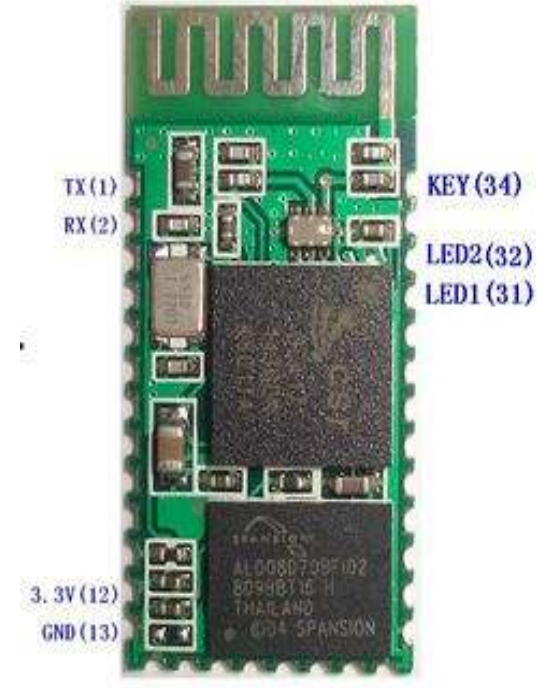

Gambar 5. Tampilan Fisik Modul Bluetooth HC-05

Dalam perancangan Bluetooth ini, menggunakan modul Bluetoot $\mathrm{HC}$ 05. Komponen ini berfungsi sebagai media komunikasi antara arduino uno dan smartphone, modul Bluetooth HC05 bekerja dengan sumber tegangan 3 Volt yang berasal dari IC Converter yang menurunkan tegangan dari 5 Volt menjadi 3 Volt. Modul Bluetooth HC05 memiliki spesifikasi sebagai berikut:

- Bluetooth Protocol: Bluetooth Specification V2.0+EDR

- Frequency: 2,4 GHz ISM band

- Modulation: GFSK (Gaussian Frequency Shift Keying)

- Emission Power: $\leq 4 \mathrm{dBm}$, Class 2

- Sensitivity: $\leq-84 \mathrm{dBm}$ at $0.1 \%$ BER

- Speed: Asynchronous: 2.1 Mbps (Max) / 160 kbps,

- Synchronous: $1 \mathrm{Mbps} / 1 \mathrm{Mbps}$

- Security: Authentication and encryption

- Profiles: Bluetooth serial port

- Power Supply: +3.3VDC 50mA

- Working Temperature: $-20 \sim+$ 75 Centigrade

- Dimension: $26.9 \mathrm{~mm} \times 13 \mathrm{~mm} \times$ $2.2 \mathrm{~mm}$ 


\section{Motor Servo}

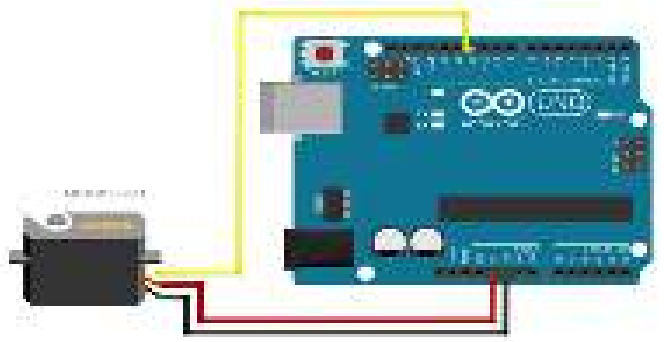

Gambar 6. Rangkaian Motor Servo

Pada rangkaian ini dikonfigurasi untuk kaki motor servo dengan mikrokontroller Atmega328 berada pada pin digital 11. Cara kerja rangkaian motor servo ketika mikrokontroller mendapat inputan dari smartphone android, sensor infrared dan sensor ldr.

\section{Rangkaian Catu Daya}

Catu daya sebagai power supply adalah sebuah piranti elektronika yang berguna sebagai sumber daya untuk piranti lain yang sangat penting. Dalam realisasi perangkat keras yang berupa 2 buah motor servo dan 1 buah kipas. pada keseluruhan rangkaian sistem di sini membutuhkan catu daya. Gambar 4.1 adalah merupakan gambar rangkaian catu daya yang terhubung dalam suatu rangkaian sistem. Uji coba dilakukan dengan menggunakan lampu led (light-emitting diode), sebagai output dari tegangan kerja pada sebuah rangkaian catu daya, uji coba rangkaian catu daya dapat di lihat pada gambar 4.1 sebagai berikut:

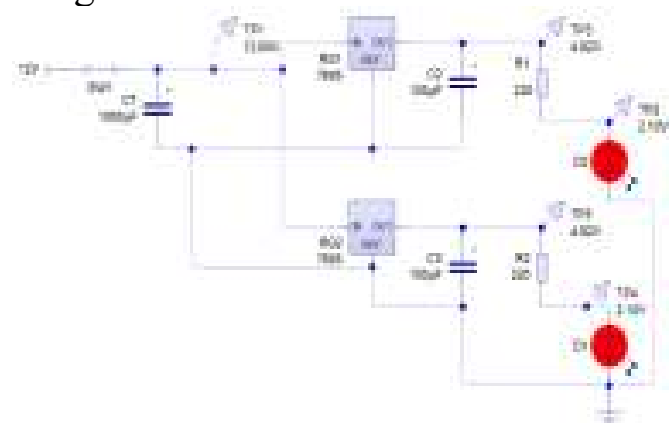

Gambar 7. Pengujian rangkaian catu daya

\section{Tampilan Program Aplikasi}

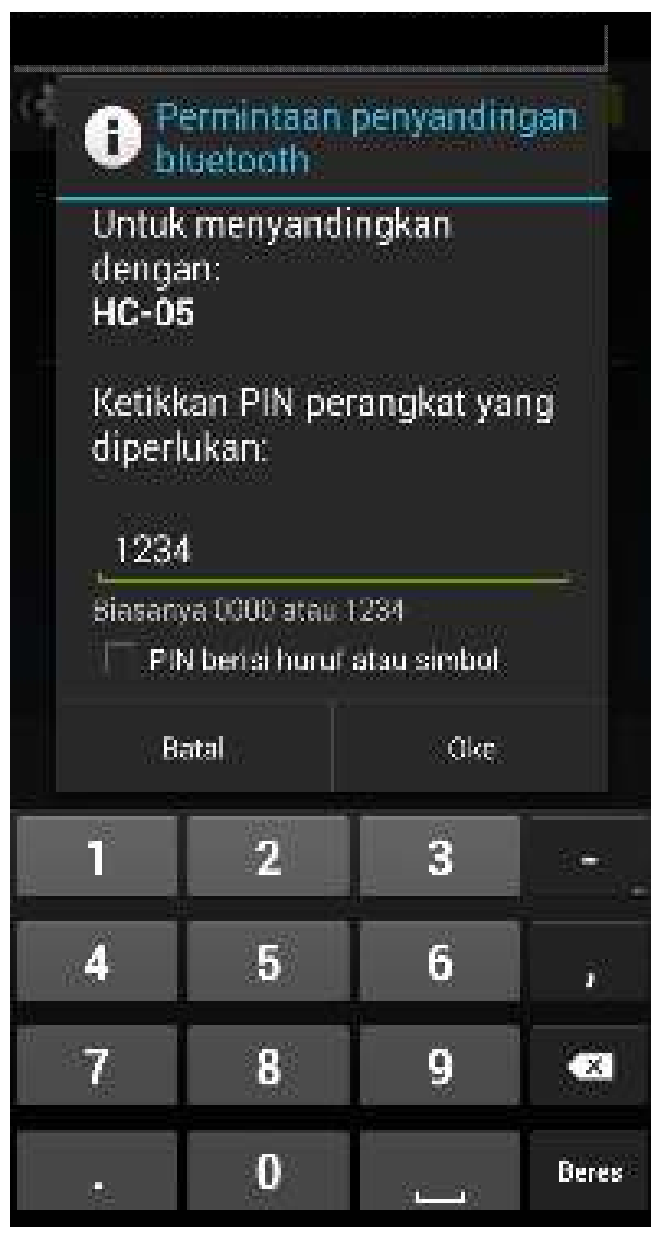

\section{Vol.2 No.1 - Februari 2016}




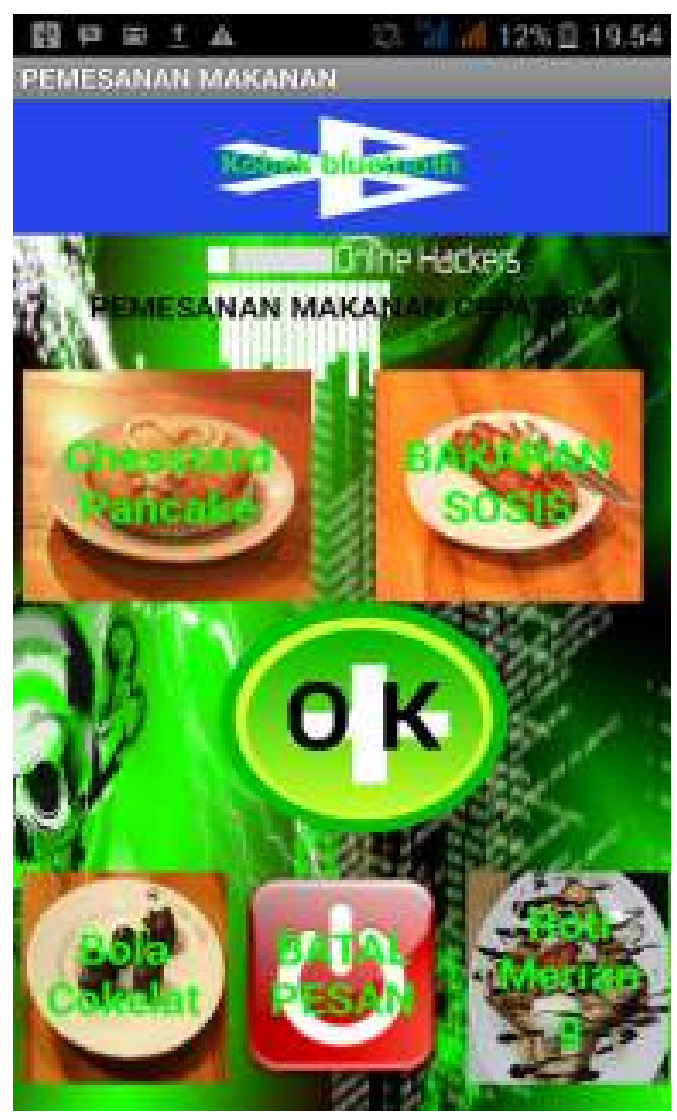

\section{Listing Program}

\#include $<$ Servo.h $>$

Servo servo;

int $\operatorname{ldr} 1=\mathrm{A} 0$;

int $1 \mathrm{dr} 2=\mathrm{A} 1$;

int $1 \mathrm{dr} 3=\mathrm{A} 2$;

int vall $=0$;

int val2 $=0$;

int val3 $=0$;

int $\operatorname{pos} 1=10$;

int $\operatorname{pos} 2=100$;

int $\operatorname{pos} 3=170$;

int star;

int flag $=0$;

int incomingByte $=0$;

int ldr1kosong=11;

int ldr2kosong $=12$;

int ldr3kosong=13;

void $\operatorname{setup}()\{$

Serial.begin (9600);

pinMode(ldr1kosong, OUTPUT);

pinMode(ldr2kosong, OUTPUT);

pinMode(1dr3kosong, OUTPUT); servo.attach(10);

servo.write(pos1);

\}

void $\operatorname{loop}()\{$

if (Serial.available ()$>0)\{$ incomingByte $=$ Serial.read(); \}

switch(incomingByte)

\{

case 'A':

servo.write(pos1);

break;

case 'B':

servo.write(pos2);

break;

case ' $\mathrm{C}$ ':

servo.write(pos3);

break;

\}

if(Serial.available ()$>0)\{$

star $=$ Serial.read () ;

flag $=0$;

\}

if( $\operatorname{star}==$ '1' $\left.^{\prime}\right)\{$

servo.write(pos1);

if $($ flag $==0)\{$

flag $=1$;

\}

\}

if $\left(\right.$ star $==$ '2' $\left.^{\prime}\right)\{$

servo.write(pos2);

if(flag $==0)\{$

flag $=1$;

\}

$$
\text { if(star }==\text { ' } 3 \text { ' })\{
$$

servo.write(pos3);

if $($ flag $==0)\{$

flag $=1$;

\}

\}

val1 =analogRead(ldr1);

if (val1 $<=800)\{$

digitalWrite(ldr1kosong, HIGH);

Vol.2 No.1 - Februari 2016 


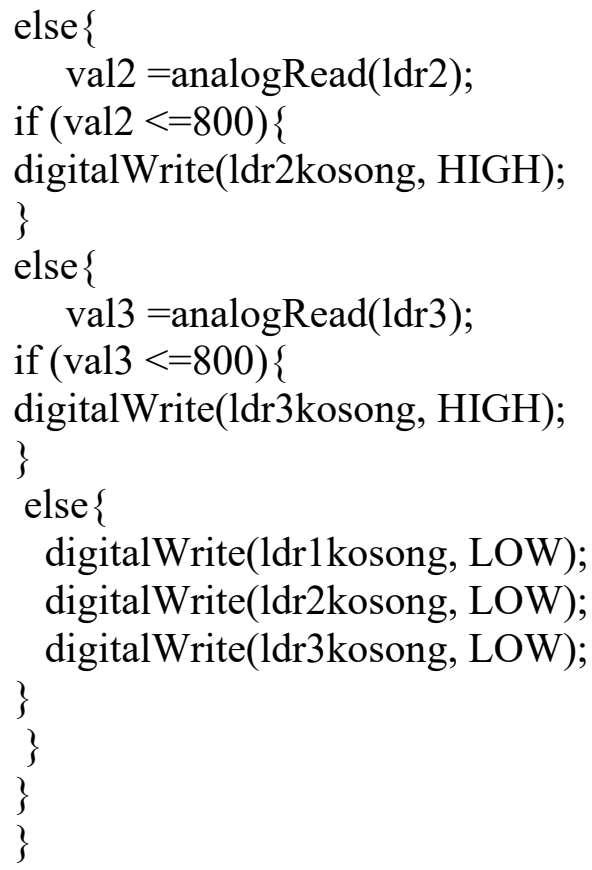

\section{KESIMPULAN}

Dari perancangan yang dilakukan dapat diperoleh kesimpulan sebagi berikut:

1. Smartphone Android KitKat dapat berinteraksi dengan arduino uno menggunakan koneksi Bluetooth. pada alat ini menggunakan Bluetooth HC-05 agar smartphone dan arduino uno dapat berkomunikasi.

2. Cara arduino uno membuat meja makanan berputar dan pesanan yang telah dipesan yaitu dengan menggunakan bantuan motor servo yang bergerak agar makanan dapat otomatis menghampiri customer.

3. Pada smartphone android KitKat harus terinstal aplikasi bluetooth terminal, agar sisstem Pemesanan makanan dapat dikendalikan melalui smartphone android KitKat.

\section{DAFTAR PUSTAKA}

[1] Saefullah, Asep, Sumardi Sadi, Yoga Bayana. 2013. Smart Wheeled Robotic (SWR) Yang Mampu Menghindari Rintangan
Secara Otomatis. Tangerang: Pergurua Tinggi Raharja. CCIT, Vol.2 No.3.

[2] Safaat, Nazruddin. 2011. Android PemrogramanAplikasi Mobile Smartphone dan Tablet PC Berbasis Android. Jakarta: Informatika.

[3] Santoso Ari Beni, Martinus, Sugiyanto. 2013. Pembuatan Otomasi Pengaturan Kereta Api, Pengereman dan Palang Pintu pada Rel Kereta Mainan Berbasis Mikokontroler. Jurnal FEMA Universitas Lampung Vol 1. No.1.

[4] Saefullah, Asep, Dewi Immaniar dan Reza Amar Juliansyah. 2015. Sistem Kontrol Robot Pemindah Barang Menggunakan Aplikasi Android Berbasis Arduino Uno. CCIT Journal Vol. 8, No. 2, Januari 2015.

[5] Komputer, Wahana. 2012. MembuatAplikasi Android Untuk Tablet danHandphone. Jakarta: PT Elex Media Komputindo

[6] Kristanti, Tanti dan Niluh Gede Radita A.K. 2012. Sistem Informasi Nilai SMPN 14 Bandung. Jurnal Sistem Informasi. Vol.7, No.1, Maret 2012.

[7] Padillah, Heru Andra, Arif Gunawan dan Wahyuni Khabzli. 2013. Kontrol Wireless Bionik Robot Jari Tangan Menggunakan Arduino. Jurnal Teknik Elektro dan Komputer Vol.1, No. 2, Oktober 2013.

[8] Prianto, Eko, K. Ima Ismara dan Andik Asmara. 2013. Desain Sistem Kendali Kecepatan dan Counter Putaran Berbasis Teknologi Otomasi Pada Industri Kecil dan Menengah. Simposium Nasional RAPI XII. 2013. 